\title{
Norwalk virus - Off and running
}

\author{
JM Conly $\mathrm{MD}^{1}$, BL Johnston $\mathrm{MD}^{2}$
}

$\mathrm{H}$ ospitals across Canada have been struggling with a series of outbreaks of viral gastroenteritis caused by the Norwalk virus (NV). Nursing homes, schools and hospitals in Alberta, British Columbia, New Brunswick and Ontario have been most affected, with additional outbreaks reported from Manitoba and Quebec (1-4).

By the end of December 2002, in Edmonton's Capital Health Region, there were 42 outbreaks directly affecting more than 1000 individuals. Thirty outbreaks of viral gastroenteritis have been reported to Public Health in the Calgary Health Region since the beginning of October 2002, with 18 of these in December alone (2). In British Columbia from January to June 2002, more than 30 gastrointestinal illness outbreaks were found by reverse transcriptase polymerase chain reaction (RTPCR) testing to be caused by Norwalk-like virus (NLV) (3).

These outbreaks, involving both patients and staff, have occurred in various closed and semiclosed populations, including long term care facilities, assisted living sites, schools and acute care facilities. In most of the outbreaks where stool samples have been obtained for testing, NLV has been identified as the causative agent. This kind of outbreak activity usually signals a high amount of illness in the community and suggests that considerable under-reporting is occurring, with a resultant underestimation of the numbers of affected people. Many acute care hospitals across southern Ontario were forced to curtail visiting hours or temporarily close wards and emergency rooms in recent weeks to try to slow the spread of the virus (4).

In addition, persistent outbreaks of gastrointestinal illness due to NLV among passengers and crew of cruise ships have been increasingly reported over the past few years. During the autumn of 2002, at least one large cruise ship was withdrawn from active service to provide an opportunity for a thorough environmental cleaning. What do we know about the NLV? What are the factors associated with its spread? The recent series of outbreaks provides an opportunity to review some of the epidemiology and features of NLV infections.

In October 1968, an outbreak of acute gastroenteritis among students and teachers in an elementary school in Norwalk, Ohio was investigated by the Centers for Disease Control and Prevention (5). During a two-day period, 50\% of the students and teachers (116 of 232) developed a gastrointestinal illness with a secondary attack rate of $32 \%$ among contacts of primary cases. The illness was characterized by nausea and vomiting in more than $90 \%$ of cases and diarrhea in $38 \%$ of affected individuals, and the duration of illness was typically 12 to $24 \mathrm{~h}$. The term 'winter vomiting disease' was coined to describe the illness. Subsequent experiments demonstrating that organism-free filtrates of stools collected from affected individuals induced similar illness in volunteers suggested that the causative agent was a small (less than $36 \mathrm{~nm}$ ), etherresistant (nonenveloped) heat-stable virus $(6,7)$. Attempts to propagate the agent in cell culture were not successful, but in 1972, Kapikian et al (8) used immune electron microscopy to identify $27 \mathrm{~nm}$ viral particles in a fecal filtrate used to induce illness in human volunteers. Virus particles were precipitated in an antigen-antibody reaction using convalescent-phase serum from a volunteer who became ill following inoculation with the fecal filtrate. Antigen-antibody complexes were then visualized using electron microscopy. Subsequent tests were done demonstrating changes between acute and convalescent serum antibody responses. From the results of all these data, NV was proposed to be the etiological agent of the Norwalk, Ohio outbreak of gastroenteritis. Subsequent studies demonstrated that other small, round-structured viruses morphologically similar to NV were associated with outbreaks of gastroenteritis $(9,10)$, but NV remained the prototype of these fecal viruses.

Regarding the current nomenclature for NV and other related small, round-structured viruses, the International Committee on Taxonomy of Viruses has recently approved several proposals submitted by the Caliciviridae Study Group (11). These proposals include the division of the family into four new genera-designated Lagovirus (rabbit hemorrhagic disease virus and European brown hare syndrome virus), Vesivirus (feline calicivirus and vesicular exanthema of swine virus), NLVs, and Sapporo-like viruses; the latter two genera are temporary names.

NLVs are a genetically and antigenically diverse group of viruses. Two human genogroups have been described genogroup I and genogroup II (12). Genogroup I contains the NV (the prototype virus), Cruise ship virus, Desert Shield virus and Southampton virus, while Genogroup II has Snow Mountain agent, Hawaii virus, Mexico virus, Toronto virus, Grimsby virus, Lordsdale virus and the White River virus. A third genogroup contains bovine strains related to NV.

NLVs represent the most important cause of gastroenteritis outbreaks worldwide $(13,14)$ and account for up to $96 \%$ of outbreaks of nonbacterial gastroenteritis in the United States

${ }^{1}$ Departments of Pathology and Laboratory Medicine, Medicine, and Microbiology Ë Infectious Diseases, University of Calgary, Calgary, Alberta; ${ }^{2}$ Queen Elizabeth II Health Sciences Centre and Dalhousie University, Halifax, Nova Scotia

Correspondence: Dr John Conly, Departments of Pathology and Laboratory Medicine, Medicine, and Microbiology $\mathcal{B}$ Infectious Diseases, Department of Medicine, Room 930, 9th Floor, North Tower, 1403 29th Street Northwest, Calgary, Alberta T2N 2 T9.

Telephone 403-944-8222, fax 403-944-1095, e-mail jconly@ucalgary.ca and Dr Lynn Johnston, Room 5014 ACC, Queen Elizabeth II

Health Sciences Centre, 1278 Tower Road, Halifax, Nova Scotia B3H 2Y9. Telephone 902-473-5553, fax 902-473-7394,

e-mail ljohnsto@dal.ca 
(15). They have been implicated in $43 \%$ of all foodborne outbreaks in England, 67\% in Sweden and $80 \%$ in the Netherlands (16-18). Outbreaks of NLV gastroenteritis more frequently affect adults and children older than five years of age. NLVs are commonly associated with outbreaks of gastroenteritis in nursing homes, homes for the aged and adult institutions. In addition, outbreaks of NLV-associated gastrointestinal illness are commonly encountered in military deployments. NLVs were the most common cause of disability among soldiers in operations Desert Storm and Desert Shield, have caused outbreaks aboard aircraft carriers (19) and have been a common problem in the Israeli military (20). Because of the low infectious dose of the agent (10 to 100 viral particles can induce symptoms), outbreaks are characterized by a high secondary attack rate. In addition to the low inoculum, prolonged asymptomatic shedding (up to two weeks after recovery), ability to resist chlorination (10 ppm chlorine) and stability in the environment (stable with freezing and at $140^{\circ} \mathrm{F}\left[60^{\circ} \mathrm{C}\right]$ ) all contribute to the highly contagious nature of NLVs. The usual source of infection is contaminated food or water (21-23), while the usual mode of transmission is direct person-to-person contact with saliva, vomit or aerosols. Transmission may also occur through contact with contaminated objects and surfaces such as showers, sinks, mats and floors (24).

The incidence of NLV appears to be higher in the fall and winter. In most documented outbreaks, the incubation period has been reported as 24 to $48 \mathrm{~h}$ and the average duration of symptoms is 12 to $60 \mathrm{~h}$. NLV gastroenteritis has some distinguishing characteristics, including diarrhea, vomiting, a short duration of illness (one to three days), and a short incubation period ( 24 to $48 \mathrm{~h}$ ). A sudden onset of symptoms is not uncommon, with no previous feelings of being 'unwell'. During an outbreak, more than $50 \%$ of infected persons experience vomiting (25). The illness is generally mild, but it can cause severe disease with associated dehydration and electrolyte imbalance that might require hospitalization and aggressive

\section{REFERENCES}

1. McCarten J. Responses to 1999-2000 flu epidemic don't apply to Norwalk, experts say. <http://cnews.canoe.ca/CNEWS/Canada/ 2002/12/06/6703-cp.html> Version current at December 2002

2. Calgary Health Region. <http://www.crha-health.ab.ca/clin/ cme/calert.htm $>$ Version current at December 2002

3. BC Centre for Disease Control. <http://www.bccdc.org/downloads/ pdf/lab/reports/calicivirus_mngt.pdf $>$ Version current at December 2002

4. Health Canada. <http://www.hc-sc.gc.ca/pphb-dgspsp/bid-bmi/dsddsm/nb-ab/2002/nb4802_e.html> Version current at December 2002

5. Adler I, Zickl R. Winter vomiting disease. J Infect Dis 1969;119:668-73.

6. Dolin R, Blacklow NH, DuPont H, et al. Biological properties of Norwalk agent of acute infectious nonbacterial gastroenteritis. Proc Soc Exp Biol Med 1972;140:578-83.

7. Dolin R, Blacklow NR, DuPont H, et al. Transmission of acute infectious nonbacterial gastroenteritis to volunteers by oral administration of stool filtrates. J Infect Dis 1971;123:307-12.

8. Kapikian AZ, Wyatt RG, Dolin R, Thornhill TS, Kalica AR, Chanock RM. Visualization by immune electron microscopy of a $27 \mathrm{~nm}$ particle associated with acute infectious nonbacterial gastroenteritis. J Virol 1972;10:1075-81.

9. Dolin R, Reichman RC, Roessner KD, et al. Detection by immune electron microscopy of the Snow Mountain agent of acute viral gastroenteritis. J Infect Dis 1982;146:184-9.

10. Thornhill TS, Wyatt RG, Kalica AR, Dolin R, Chanock RM, treatment with intravenous fluids. In a recently described military setting (26), three patients presented with severe acute illness characterized by headache, neck stiffness, photophobia, gastrointestinal symptoms and obtundation requiring ventilatory support, which made the initial diagnosis elusive. In addition, one patient had an associated disseminated intravascular coagulopathy. Severe illness with NLVs has been associated with group $\mathrm{O}$ blood phenotype (27).

The diagnosis of NLV gastroenteritis from stool specimens is difficult and relies on direct visualization of the viral particles by electron microscopy, the identification of viral RNA by RTPCR, and/or evidence of a specific antibody response in acuteand convalescent-phase serum specimens (28). Further characterization of the NLV into genogroups is possible by sequence analysis at research laboratories. In Canada, detection by PCR is usually limited to provincial or federal reference laboratories. Health care providers consider the diagnosis on clinical grounds without seeking laboratory confirmation. Consequently, many outbreaks probably go unreported, but attribution to NLVs has been infrequent because of the difficulty of diagnosis. Simpler, less time- and labor-intensive diagnostic methods are under development, including enzyme immunoassay antigen-capture assays, which are being tested in Japan and Europe but have not yet been evaluated fully in North America.

Interruption of the spread in an institutional setting can be difficult. However, the appropriate application of infection control measures should bring it under control (25). Measures that have been used include the following: contact barrier precautions for symptomatic persons, exclusion of ill staff from work until they are symptom free for $48 \mathrm{~h}$, rigorous attention to handwashing in both patient and staff populations, regular disinfection of washrooms and all hand contact surfaces as needed, and encouraging visitors to wash their hands before and after visiting the facility. Waterless hand rinses containing at least $60 \%$ alcohol can be used for hand hygiene if hands are not visibly soiled.

Kapikian AZ. Detection by immune electron microscopy of 26-27 nm virus-like particles associated with two family outbreaks of gastroenteritis. J Infect Dis 1977;135:20-7.

11. Green KY, Ando T, Balayan MS, et al. Taxonomy of the caliciviruses. J Infect Dis 2000;181(Suppl 2):S322-30.

12. Ando T, Noel JS, Fankhauser RL. Genetic classification of "Norwalk-like Viruses". J Infect Dis 2000;181:S336-48.

13. Kapikian AZ. The discovery of the 27-nm Norwalk virus: An historic perspective. J Infect Dis 2000;181(Suppl 2):S295-302.

14. Monroe SS, Ando T, Glass RI. Introduction: Human enteric calicivirus - an emerging pathogen whose time has come. J Infect Dis 2000;181:S249-51.

15. Glass RI, Noel J, Ando T, et al. The epidemiology of enteric Calicivirus from humans: a reassessment using new diagnostics. J Infect Dis 2000;181(Suppl 2):S254-61.

16. Evans HS, Madden P, Douglas C, et al. General outbreaks of infectious intestinal disease in England and Wales: 1995 and 1996. Commun Dis Public Health 1998;1:165-71.

17. Hedlund KO, Rubilar-Abreu E, Svensson L. Epidemiology of calicivirus infections in Sweden, 1994-1998. J Infect Dis 2000;181(Suppl 2):S275-80.

18. Koopmans M, Vinje J, de Wit M, Leenen I, van der Poel W, van Dujnhoven Y. Molecular epidemiology of human enteric caliciviruses in the Netherlands. J Infect Dis 2000;181(Suppl 2):S262-9.

19. McCarthy M, Estes MK, Hyams KC. Norwalk-like virus infection in 
military forces: Epidemic potential, sporadic disease, and the future direction of prevention and control efforts. J Infect Dis 2000;181(Suppl 2):S387-91

20. Cohen D, Monroe SS, Haim M, et al. Norwalk virus gastroenteritis among Israeli soldiers: Lack of evidence for flyborne transmission. Infection 2002;30:3-6.

21. Dowell SF, Groves C, Kirkland KB, et al. A multistate outbreak of oyster-associated gastroenteritis: Implications for interstate tracing of contaminated shellfish. J Infect Dis 1995;171:1497-503.

22. Kukkula M, Maunula L, Silvennoinen E, Von Bonsdorff CH.

Outbreak of viral gastroenteritis due to drinking water contaminated by Norwalk-like viruses. J Infect Dis 1999;180:1771-6.

23. Beller M, Ellis A, Lee SH, et al. Outbreak of viral gastroenteritis due to a contaminated well. JAMA 1997;278:563-8.
24. Glass RI, Noel J, Ando T, et al. The epidemiology of enteric caliciviruses from humans: A reassessment using new diagnostics. J Infect Dis 2000;181(Suppl 2):S254-61.

25. Centers for Disease Control and Prevention. Norwalk-like viruses. Public health consequences and outbreak management. MMWR Morb Mortal Wkly Rep 2001;50(RR-9):1-18.

26. Outbreak of acute gastroenteritis associated with Norwalk-like viruses among British military personnel — Afghanistan, May 2002. MMWR Morb Mortal Wkly Rep 2002;51:477-9.

27. Hutson AM, Atmar RL, Graham DY, Estes MK. Norwalk virus infection and disease is associated with $\mathrm{ABO}$ histo-blood group type. J Infect Dis 2002;185:1335-7.

28. Glass RI, Noel J, Ando T, et al. The epidemiology of enteric caliciviruses from humans: a reassessment using new diagnostics. J Infect Dis 2000;181:S254-S61. 


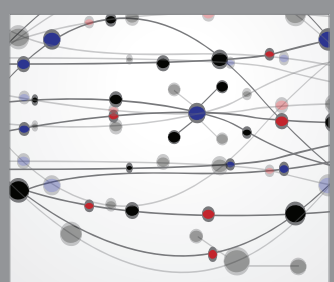

The Scientific World Journal
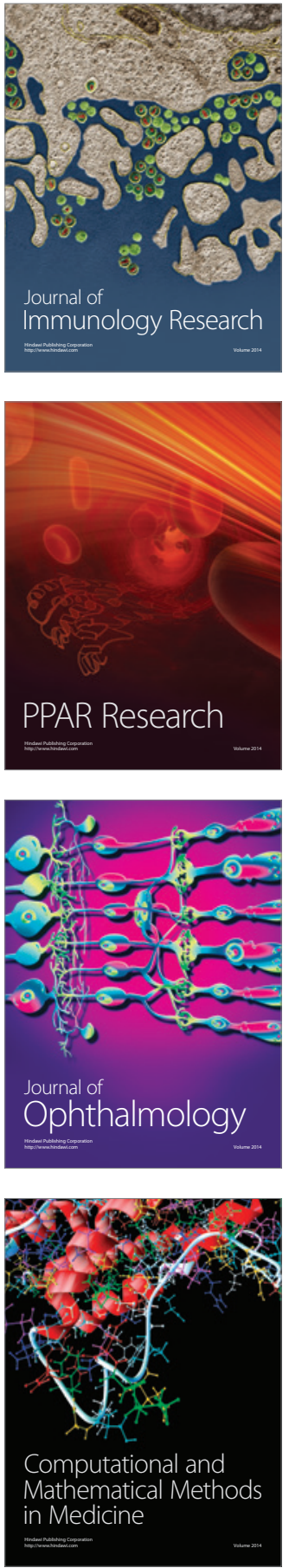

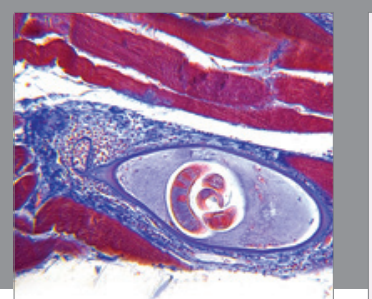

Gastroenterology Research and Practice

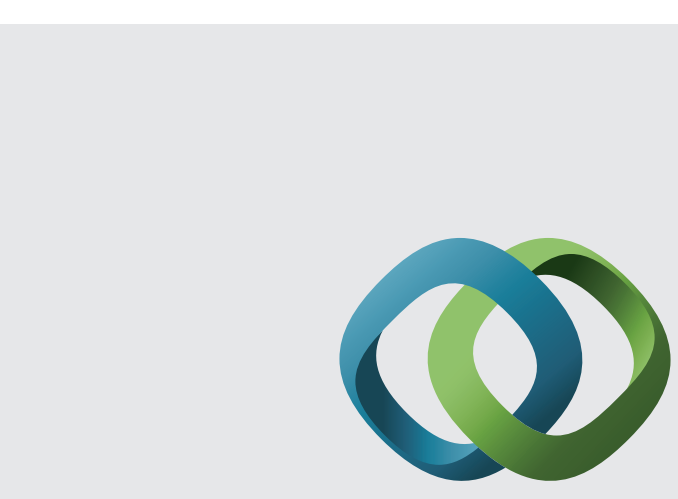

\section{Hindawi}

Submit your manuscripts at

http://www.hindawi.com
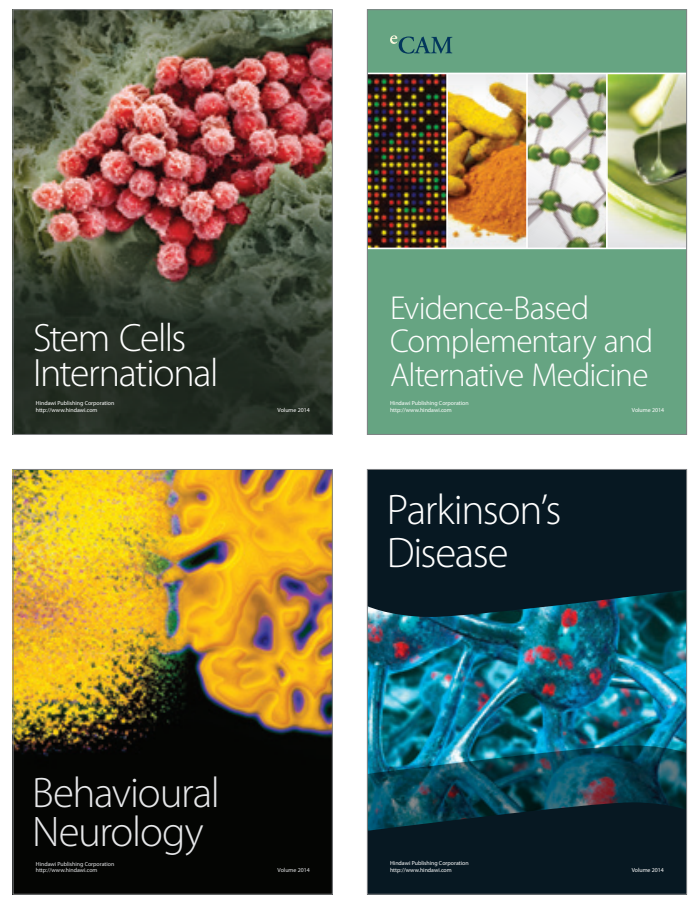
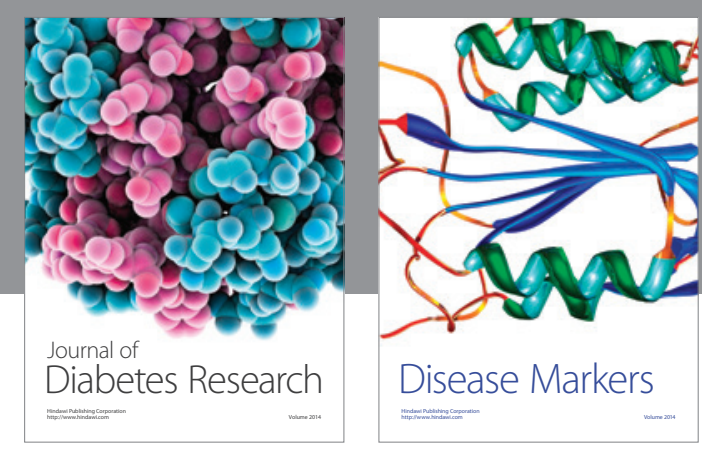

Disease Markers
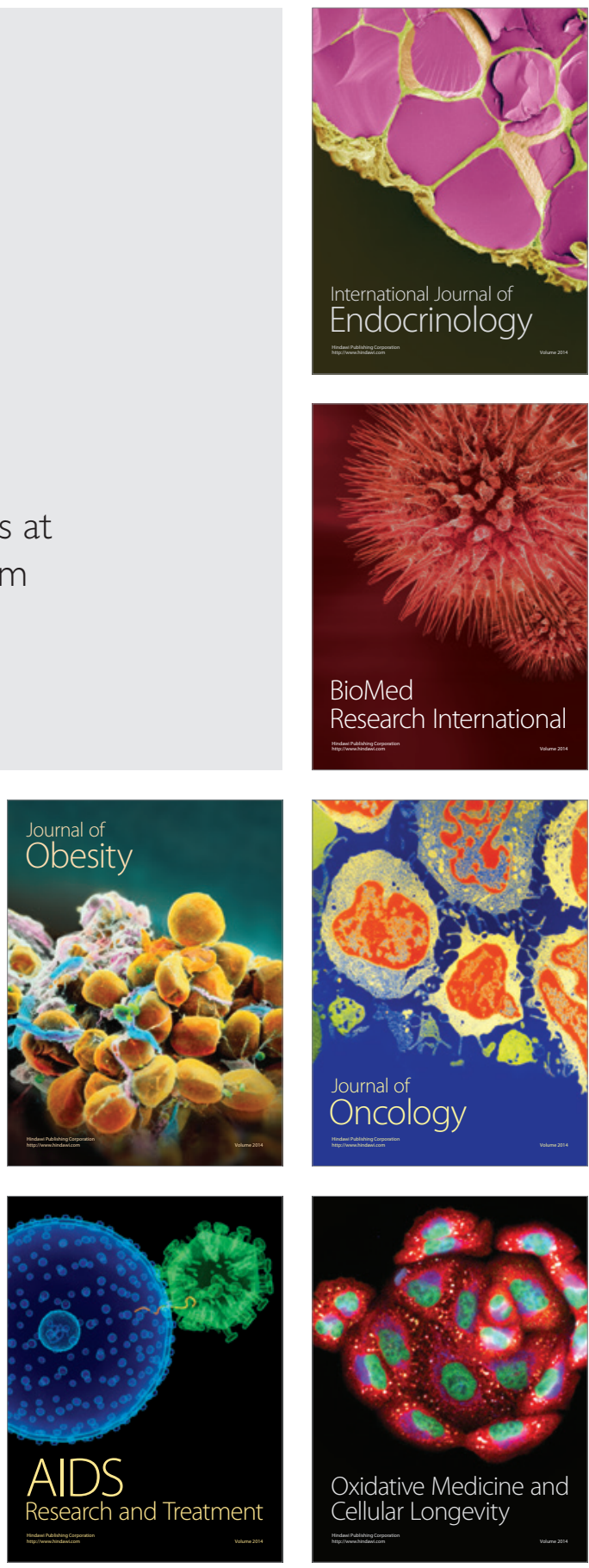